\title{
DESINFESTAÇÃO DE SEMENTES E MULTIPLICAÇÃO IN VITRO DE GUABIJUZEIRO A PARTIR DE SEGMENTOS APICAIS JUVENIS (Myrcianthes pungens O.BERG) D. LEGRAND ${ }^{1}$
}

\author{
LUANA DOS SANTOS DE SOUZA², CLAUDIMAR SIDNEI FIOR ${ }^{3}$, \\ PAULO VITOR DUTRA DE SOUZA ${ }^{4}$, SERGIO FRANCISCO SCHWARZ ${ }^{4}$
}

RESUMO - O guabijuzeiro é uma árvore perenifólia de 15 a 25 metros de altura. Seus frutos são comestíveis e contêm uma ou duas sementes. Ocorre no Brasil desde São Paulo até o Rio Grande do Sul. Dentre as fruteiras silvestres, esta espécie possui várias características que a tornam com potencialidades de utilização comercial, nas quais as mais importantes estão relacionadas com a frutificação. Sua propagação é realizada por sementes e são escassas as informações sobre a propagação vegetativa. Diante disto, o objetivo deste trabalho foi estudar a desinfestação de sementes e a multiplicação in vitro de guabijuzeiro. Os experimentos foram realizados no Laboratório de Biotecnologia em Horticultura da Faculdade de Agronomia da UFRGS. O teste de desinfestação iniciou com a imersão das sementes em etanol $70 \%$ por 1 minuto, seguido de solução de hipoclorito de sódio nas concentrações de $0 ; 2 ; 4 ; 6$ e 8\%. O meio de cultura utilizado nos experimentos foi o WPM com 30 g.L.-1 de sacarose e 7 g.L. L $^{-1}$ de ágar. Para o teste de multiplicação, foram utilizados segmentos apicais de plântulas provenientes de sementes germinadas in vitro. Os tratamentos consistiram em concentrações de BAP $\left(0 ; 0,2 ; 0,4 ; 0,6 ; 0,8 ; 1\right.$ e 2 mg. $\left.\mathrm{L}^{-1}\right)$. Como resultados, as concentrações entre 4 e $6 \%$ de hipoclorito de sódio mostram-se mais vantajosas, pois além de serem eficientes na desinfestação, influenciarem positivamente a germinação. Para a multiplicação, o cultivo de segmentos apicais em meio com o BAP em concentrações de até $1 \mathrm{mg} . \mathrm{L}^{-1}$ foi eficiente.

Termos para Indexação: Assepsia, frutífera nativa, germinação, multiplicação in vitro.

\section{DISINFESTATION OF SEEDS AND IN VITRO MULTIPLICATION OF GUABIJUZEIRO FROM APICAL JUVENILES SEGMENTS (Myrcianthes pungens O.BERG) D. LEGRAND}

\begin{abstract}
The guabijuzeiro is an evergreen tree 15-25 meters high. Occurs in Brazil from São Paulo to Rio Grande do Sul. Among the wild fruits this species has several characteristics which make it with potential for commercial use, in which the most important are related to fructification. Its propagation is carried out by seed and little information on vegetative propagation. Hence, the objective was to study the disinfection of seeds and in vitro multiplication of guabijuzeiro. The experiments were performed at the Laboratory of Biotechnology in Horticulture, Faculdade de Agronomia, Universidade Federal do Rio Grande do Sul. The test began with the disinfestation soaking in 70\% ethanol for 1 minute, followed by a solution of sodium hypochlorite at concentrations of $0 ; 2 ; 4 ; 6$ and $8 \%$. The culture medium used in experiments was WPM with 30 g.L. $\mathrm{L}^{-1}$ sucrose and 7 g.L. $\mathrm{L}^{-1}$ of agar. For the multiplication test were used apical segments of seedlings from seeds germinated in vitro. The treatments consisted of BAP concentrations $(0 ; 0,2 ; 0,4 ; 0,6 ; 0,8 ; 1$ and $\left.2 \mathrm{mg} . \mathrm{L}^{-1}\right)$. As a result the concentrations between 4 and $6 \%$ of sodium hypochlorite are more advantageous, as well as being effective in disinfestation, positively influence the germination. For multiplication, the cultivation of apical segments on medium with BAP at concentrations of up $1 \mathrm{mg} .1^{-1}$ was effective.
\end{abstract}

Index terms: Asepsis, native fruit, germination, in vitro multiplication.

\footnotetext{
'(Trabalho 161-10). Recebido em: 19-07-2010. Aceito para publicação em: 21-12-2010. Trabalho desenvolvido como parte da dissertação de mestrado do primeiro autor. Financiado pela Capes.

${ }^{2}$ Bióloga, Mestranda do Programa de Pós-Graduação em Fitotecnia da UFRGS. E-mail: luana1981@terra.com.br

${ }^{3}$ Eng. Agrônomo, Doutorando do Programa de Pós-Graduação em Fitotecnia da UFRGS. Pesquisador do Jardim Botânico da Fundação Zoobotânica do RS. E-mail: csfior@fzb.rs.gov.br

${ }^{4}$ Eng. Agr., Doutor, Professor do Departamento de Horticultura e Silvicultura e do Programa de Pós-Graduação em Fitotecnia da UFRGS - Faculdade de Agronomia da UFRGS. Bolsista CNPq. E-mail: pvdsouza@ufrgs.br, schwarz@ufrgs.br * Autor para correspondência
} 


\section{INTRODUÇÃO}

Espécies nativas pertencentes à família Myrtaceae são abundantes em todo o território brasileiro e em alguns países latino-americanos. Várias espécies dessa família, principalmente as nativas do Brasil, têm frutos comestíveis utilizados há milênios por populações indígenas. Seu uso potencial é enorme, não somente pela possibilidade de consumo do fruto in natura, como também para industrialização, como no caso de compostos em bebidas (licores, sucos), geleias, doces, sorvetes, picolés, condimentos, entre outras formas de uso. Além disso, há várias espécies com valor ornamental (LORENZI, 2002; MATTOS, 1993).

O guabijuzeiro (Myrcianthes pungens (Berg) Legr.) é uma planta arbórea nativa no Brasil. Apresenta copa perenifólia e arredondada, podendo atingir de 15 a 25 metros de altura. Seus frutos são do tipo baga globosa, contendo de uma a duas sementes reniformes, medindo de 6 a 7 milímetros (LORENZI, 2002; MARCHIORI; SOBRAL,1997). Trabalhando com sementes de guabijuzeiro oriundos de seis procedências, Fior et al. (2010) obtiveram germinação acima de $80 \%$ em ambiente controlado, e emergência entre 66 a 91\% em casa de vegetação. Estes autores mencionam ainda que sementes desta espécie coletadas com elevada qualidade inicial e armazenadas em condições de câmara fria (temperaturas próximas a $5^{\circ} \mathrm{C}$ e umidade relativa do ar em torno de $45 \%$ ) podem ter sua longevidade estendida por cerca de oito meses.

A propagação do guabijuzeiro por sementes apresenta como desvantagem a segregação genética, originando plantas com grande variabilidade e prolongado período juvenil (PÁDUA, 1983).

Donadio et al. (2002) ressaltam que o tipo ideal de propagação comercial para a maioria das espécies frutíferas é a vegetativa. A micropropagação destaca-se como alternativa, pois, segundo Cid et al. (1997), ela tem sido utilizada para obtenção de mudas de espécies florestais nativas visando à exploração na Fruticultura.

Uma das vantagens desta técnica é a obtenção de grande número de mudas a partir de um número restrito de plantas-elite (LIEW; TEO, 1998).

Um dos maiores problemas no estabelecimento de tecidos vegetais in vitro é a contaminação por microrganismos, principalmente quando se trabalha com espécies lenhosas (BONGA, 1982). Uma das maneiras de facilitar a obtenção de material vegetal sem contaminação é a germinação in vitro, para isso é necessário realizar uma desinfestação eficiente das sementes.
Além da vantagem da obtenção de tecidos menos contaminados, a utilização de material juvenil já estabelecido in vitro pode ser vantajosa, pois estes tecidos são mais responsivos à aplicação de fitorreguladores. Além disso, potencialmente, podem originar explantes com elevada capacidade de desenvolvimento (GRATTAPAGLIA; MACHADO, 1998). Logo, esse tipo de explante pode orientar e auxiliar a elaboração de protocolos para posterior aplicação em tecidos de plantas adultas.

Os relatos na literatura sobre a propagação vegetativa de guabijuzeiro são escassos, tornando-se indispensável a investigação científica.

Diante disso, realizou-se o presente estudo com o objetivo de testar concentrações de hipoclorito de sódio $(\mathrm{NaOCl})$ na desinfestação e germinação in vitro de sementes de guabijuzeiro, bem como a indução à multiplicação com concentrações de citocinina em explantes oriundos de plântulas.

\section{MATERIAL E MÉTODOS}

Os experimentos foram realizados no Laboratório de Biotecnologia em Horticultura da Faculdade de Agronomia da UFRGS. O meio de cultura utilizado nos experimentos foi o WPM (Wood Plant Medium (LLOYD; McCOWN,1980)), com 30 g.L. ${ }^{-1}$ de sacarose e 7 g.L. ${ }^{-1}$ de ágar $\left(\right.$ Merck $\left.^{\circledR}\right)$. $\mathrm{O}$ pH foi ajustado em 5,8 antes da esterilização, a qual foi realizada em autoclave por 15 minutos sob temperatura de $120^{\circ} \mathrm{C}$ e pressão de $1,2 \mathrm{~atm}$. Quando utilizado fitorregulador, este foi adicionado ao meio de cultura antes da esterilização. Após a inoculação, as culturas foram mantidas em sala de crescimento com temperatura de $25 \pm 3^{\circ} \mathrm{C}$, e fotoperíodo de 16 horas (intensidade luminosa de 3 Klux, lâmpadas fluorescentes de 40W).

\section{vegetal}

Obtenção e caracterização do material

Foram coletados frutos de duas plantas situadas lado a lado, na Estação Experimental da Fundação Estadual de Pesquisa Agropecuária (FEPAGRO), em Maquiné-RS (GPS: 29³9'46,2” S; 50¹3'20,5” O). As plantas eram bastante semelhantes, tanto em dimensões das copas como no diâmetro do tronco. Os frutos de cada planta apresentavam aspecto típico da fase de maturação (coloração roxo-escura do epicarpo). Logo após a coleta, os frutos de ambas as matrizes foram levados para o laboratório e homogeneizados, constituindo um lote. Os frutos foram despolpados sob água corrente. Logo em seguida, foram separadas 3 repetições de 10 sementes para o teste de teor de água. Este foi realizado através da diferença percentual de massa das sementes após secagem em 
estufa por $24 \mathrm{~h}$ a $105 \pm 3^{\circ} \mathrm{C}$ (BRASIL, 1992).

Desinfestação e germinação de sementes in vitro

Uma amostra aleatória de 500 sementes foi separada em cinco subamostras de 100 sementes (com tegumento), para a realização do teste de desinfestação, que iniciou com a imersão em etanol $70 \%$ por 1 minuto, seguido de solução de hipoclorito de sódio nas concentrações de $0 ; 2 ; 4 ; 6$ e $8 \%(\mathrm{v} / \mathrm{v})$, acrescido de 5 gotas $\mathrm{L}^{-1}$ de Tween $20^{\circledR}$, por 20 minutos. Posteriormente, as sementes foram levadas para a câmara de fluxo laminar e lavadas em água destilada estéril (três enxágues) e estabelecidas em tubos de ensaio 25 x $150 \mathrm{~mm}$, com $10 \mathrm{~mL}$ de meio de cultivo cada, uma semente por tubo. O delineamento foi o inteiramente casualizado com quatro repetições de 25 sementes, totalizando 100 sementes por tratamento. Foram avaliados os percentuais de contaminação e germinação aos 30 dias, e mensurado o vigor das sementes através do cálculo do tempo médio de germinação (TMG) e do índice de velocidade de germinação (IVGM), através das fórmulas: TMG - Conforme Silva e Nakagawa (1995), com base na soma do número de sementes germinadas em cada avaliação, dividido pelo respectivo tempo, com o resultado expresso em dias após a semeadura; IVGM - Conforme Silva e Nakagawa (1995) modificada por Santana e Ranal (2004), com base na soma do número de sementes germinadas em cada avaliação, dividido pelo respectivo tempo, dividindo-se o resultado final pelo número total de sementes germinadas em cada repetição.

\section{Multiplicação}

Foram utilizadas plântulas provenientes de sementes germinadas in vitro, com 90 dias após a semeadura. Cada explante constituiu-se de um segmento apical com aproximadamente $0,4 \mathrm{~cm}$ de comprimento. Os explantes foram inoculados em frascos de vidro com $8 \mathrm{~cm}$ de altura por $6 \mathrm{~cm}$ de diâmetro, contendo, aproximadamente, $30 \mathrm{~mL}$ de meio de cultura, fechados com tampa de polietileno de alta densidade.

Os tratamentos foram constituídos por diferentes concentrações de $\mathrm{BAP}(0 ; 0,2 ; 0,4 ; 0,6 ; 0,8$; 1 e $\left.2 \mathrm{mg} . \mathrm{L}^{-1}\right)$ em um delineamento experimental completamente casualizado, com quatro repetições por tratamento, sendo três frascos com três segmentos apicais em cada repetição.

Após trinta dias da inoculação, foram avaliadas a porcentagem de brotação e a oxidação, e as médias do número de folhas, altura de brotações por explante.

Os dados de cada variável de ambos os experimentos foram submetidos a testes de normalidade e igualdade das variâncias, sendo transformados quando necessário. Posteriormente, procedeu-se à análise de variância (ANOVA), e quando esta foi significativa, realizou-se teste de comparação de médias, a 5\% de probabilidade de erro. Procedeu-se também à análise de regressão polinomial em ambos os experimentos.

\section{RESULTADOS E DISCUSSÃO}

\section{in vitro}

\section{Desinfestação e germinação de sementes}

Logo após a coleta, as sementes apresentaram teor de água de $38,7 \%$. Este valor elevado no estádio de maturação é característico de espécies recalcitrantes, e estão de acordo com resultados encontrados por Andrade (2002), que classificou as sementes de $M$. pungens como intolerantes à dessecação.

No tratamento-testemunha ( $0 \%$ de hipoclorito de sódio), ocorreu $100 \%$ de contaminação. Nos demais, houve baixa contaminação (entre 2\% e 14\%), sem diferença significativa entre as concentrações de hipoclorito de sódio (Tabela 1).

Nos tratamentos com $4 \%, 6 \%$ e $8 \%$ (de cloro ativo), verificou-se $98 \%, 92 \%$ e $91 \%$ de germinação, respectivamente (Tabela 1). Resultados semelhantes foram encontrados por Picolotto et al. (2007), os quais concluíram que o hipoclorito de sódio a 5\% é eficiente como desinfestante na contaminação de jabuticabeira (Myrciaria spp.), proporcionando redução nas taxas de contaminação.

Assim como constatado neste trabalho, Hanrry e Thorpe (1994) obtiveram bons resultados na desinfestação de sementes de Pinus banksiana, expostas à concentração de $6 \%$ de hipoclorito de sódio durante 20 minutos.

Segundo Rocha (2005), o hipoclorito de sódio é um potente oxidante, e sua ação pode ser resultante de modificações nas propriedades das membranas celulares do tegumento ou no fornecimento de oxigênio adicional para a semente, aumentando, dessa forma, a porcentagem de germinação. Isso pode explicar o fato de os tratamentos com $4 \%, 6 \% \mathrm{e}$ $8 \%$ de hipoclorito de sódio apresentarem germinação superior ao tratamento com $2 \%$ de hipoclorito de sódio. Provavelmente, essas concentrações mais elevadas tenham aumentado a permeabilidade do tegumento das sementes de guabijuzeiro, promovendo maior germinação.

As concentrações de cloro ativo não afetaram o vigor das sementes de guabijuzeiros mensurado pelo TMG (dias) e IVGM (Tabela 1).

A análise de regressão demonstra uma 
tendência quadrática da porcentagem de germinação em relação à concentração de hipoclorito, sendo que o ponto de máxima resposta, de acordo com a fórmula obtida, é de 5,6\%. Possivelmente, concentrações acima de $8 \%$ poderiam ser fitotóxicas, prejudicando a germinação (Figura 1).

\section{Multiplicação}

A porcentagem de explantes com brotações e o número de folhas por brotação apresentaram tendência linear descendente em relação ao aumento na concentração de BAP no meio de cultivo, enquanto o número de brotação por explante apresentou tendência quadrática, tendo como ponto de máxima resposta, conforme a equação, $0,45 \mathrm{mg} / \mathrm{L}$ (Figura 2).

Resultados diferentes foram relatados por Nascimento et al. (2008), avaliando a influência do BAP na micropropagação de uvaieira (Eugenia pyriformis), que observaram maior número e comprimento de brotações, folhas e gemas por explante na concentração de $1 \mathrm{mg} . \mathrm{L}^{-1}$ de BAP.

Souza et al. (2008), estudando a multiplicação in vitro de pitangueira (Eugenia uniflora), avaliaram diferentes tipos (BAP; 2iP; zeatina) e concentrações $(0 ; 5$ e $10 \mu \mathrm{M})$ de citocininas em meio WPM. Os autores concluíram que, para a multiplicação in vitro de pitangueira, a concentração de $5 \mu \mathrm{M}$ (1,13 mg.L $\left.\mathrm{L}^{-1}\right)$ de BAP é eficiente e tem menor custo.

Souza (2007), trabalhando com multiplicação in vitro de goiabeira-serrana, araçazeiro e pitangueira, utilizou os meios de cultura MS e WPM, com adição de BAP na concentração de 2,2 $\mu \mathrm{M}(0,5$ $\left.\mathrm{mg} . \mathrm{L}^{-1}\right)$ ou ausência desta citocinina. Observou que, para o número de brotações por explante, não houve diferença entre o tipo de meio de cultura sem adição de BAP, mas verificou que o meio WPM favoreceu o número de brotações quando em presença do BAP.

Uematsu et al. (1999) propagaram pitangueira utilizando brotações alongadas em meio MS. Observaram que o meio de cultura suplementado com $0,2 \mathrm{mg} . \mathrm{L}^{-1} \mathrm{BAP}$ foi adequado para a regeneração e a proliferação das brotações.

No presente trabalho, o número de folhas por explante nos tratamentos com concentrações de 0,$2 ; 0,4 ; 0,6$ e $0,8 \mathrm{mg} \cdot \mathrm{L}^{-1}$ de BAP foram superiores aos demais, com um número médio de folhas entre 1,65 e 2,81, não apresentando diferenças entre estes $(\mathrm{P}=0,039)$. Os tratamentos com concentrações de 1 e 2 mg.L. $\mathrm{L}^{-1}$ de BAP e Testemunha (sem adição de hormônio), que apresentaram menor número de folhas, não apresentaram diferenças estatísticas entre si (dados não apresentados).

Conforme o aumento da concentração de BAP no meio de cultura, maior foi a oxidação dos explantes (Figura 2). Com resultado similar, Lattuada (2010), observou que doses mais altas de $\operatorname{BAP}(0 ; 0,1 ; 0,2 \mathrm{e}$ $\left.0,5 \mathrm{mg} . \mathrm{L}^{-1}\right)$ foram fitotóxicas para a multiplicação in vitro de pitangueira (Eugenia uniflora). As plantas da família das myrtaceas são ricas em compostos fenólicos, principalmente as lenhosas, como o guabijuzeiro, e estes compostos dificultam o estabelecimento inicial do cultivo in vitro. A concentração de fitorreguladores no meio de cultivo pode influenciar na oxidação dos explantes, como foi observado neste trabalho.

O que pode ter contribuído para a oxidação dos explantes é o desequilíbrio entre citocinina e auxina. De acordo com Silva (2007), calos de eucalipto oxidaram em maior intensidade, quando desenvolvidos em meios com relações desequilibradas de fitorreguladores, seja auxina em relação à citocinina ou vive-versa. Resultado semelhante foi obtido por Hubner et al. (2007), pois a maior oxidação de explantes de Aspidosperma ramiflorum ocorrera em tratamentos com maior proporção de auxina em relação à citocinina.

A altura das brotações variou entre 0,15 e 0,33 , não havendo diferença entre os tratamentos $(\mathrm{P}=0,377)$. Resultados diferentes foram relatados por Rogalski et al. (2003), onde a utilização de BAP em concentrações maiores que $0,5 \mathrm{mg} \cdot \mathrm{L}^{-1}$ reduziram a altura dos brotos de ameixeira 'Santa Rosa' in vitro, na fase de multiplicação.

TABELA 1- Porcentagem de contaminação, germinação e vigor calculado pelo tempo médio de germinação (TMG) e índice de velocidade de germinação (IVGM) de sementes de guabijuzeiro logo após a coleta e semeadas em meio de cultura WPM. UFRGS, Porto Alegre-RS, 2009.

\begin{tabular}{ccccc}
\hline $\begin{array}{c}\text { Trat. } \\
\text { (Conc. NaOCl) }\end{array}$ & Contaminação & Germinação (\%) & TMG (dias) & IVGM \\
\hline 0 & $100 \mathrm{~b}$ & $0 \mathrm{c}$ & - & - \\
2 & $14 \mathrm{a}$ & $68 \mathrm{~b}$ & 19,1 & 0,061 \\
4 & $6 \mathrm{a}$ & $98 \mathrm{a}$ & 17,2 & 0,065 \\
6 & $2 \mathrm{a}$ & $92 \mathrm{a}$ & 17,2 & 0,064 \\
8 & $6 \mathrm{a}$ & $91 \mathrm{a}$ & 18,2 & 0,063 \\
\hline Valor P & $<0,001$ & $<0,001$ & 0,207 & 0,7128 \\
\hline CV (\%) & 17 & 8,3 & 7,6 & 8,7 \\
\hline
\end{tabular}

Médias seguidas pela mesma letra não diferem estatisticamente, pelo teste de Tukey, ao nível de 5\% de probabilidade de erro. Os dados foram transformados em $\sqrt{x}$. 


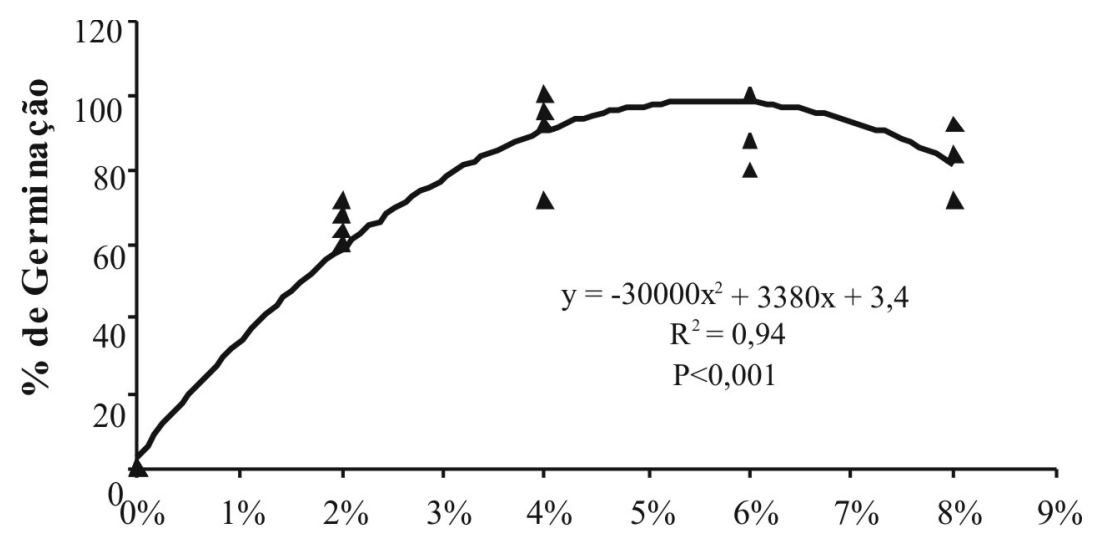

Concentração de cloro ativo

FIGURA 1 - Porcentagem de germinação de sementes de guabijuzeiro submetidas a desinfestação em diferentes concentrações de hipoclorito de sódio. Porto Alegre-RS, 2009.

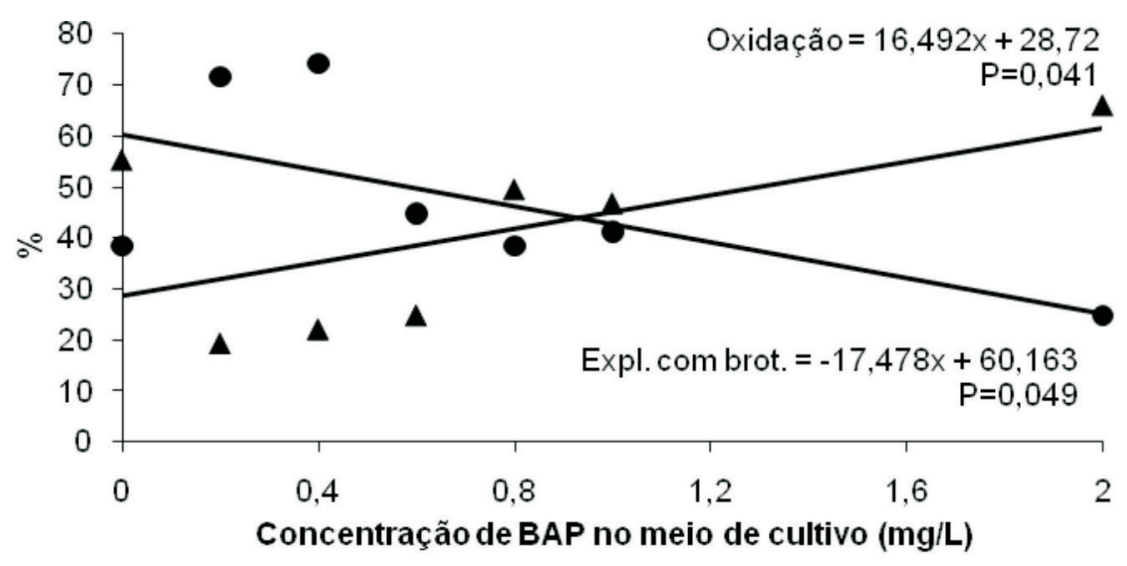

-Expl. c/brotaçöes $\quad \Delta$ Oxidaçäo

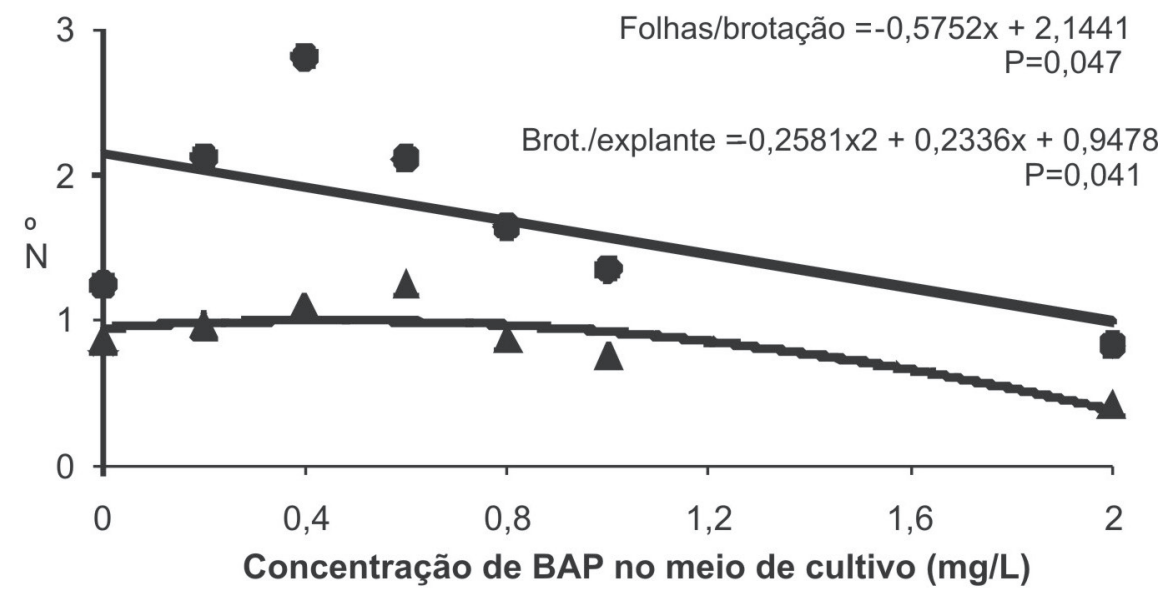

- $\mathrm{N}^{\circ}$ de folhas/planta $\Delta \mathrm{N}^{\circ}$ de brot. /Expl.

FIGURA 2 - Porcentagem de explantes com brotação e oxidação, número de brontações e folhas de guabijuzeiro em meio de cultivo com diferentes concentrações de BAP. Porto Alegre, RS, 2009. 


\section{CONCLUSÕES}

1-A desinfestação das sementes de guabijuzeiro com solução de hipoclorito de sódio de 4 a $6 \%$ de cloro ativo é eficiente e não prejudica a germinação.

2-A multiplicação in vitro, a partir de explantes de plântulas de guabijuzeiro, é satisfatória em meio com BAP em concentrações de até $1 \mathrm{mg} . \mathrm{L}^{-1}$.

\section{REFERÊNCIAS}

ANDRADE, R. N. B. Germinação de sementes de plantas ornamentais ocorrentes no Rio Grande do Sul. 2002. 110f. Tese (Doutorado em Botânica) - Instituto de Biociências, Universidade Federal do Rio Grande do Sul, Porto Alegre, 2002.

BONGA, J. M. Tissue culture techniques. In: BONGA, J. M.; DURZAN, D. J. Tissue culture in forestry. 2. ed. Dordrecht: Martinus Nijhoff, 1982. p. 4-35.

BRASIL. Ministério da Agricultura Pecuária e Abastecimento. Instrução Normativa $n^{\circ} 136$, de 31 de março de 1999. Diário Oficial da República Federativa do Brasil, Brasília, Seção 1, p.25, $1^{\circ}$ de abril 1992.

CID, L. P. B.; GOMES, A. C. M.; COSTA, S. B. R.; TEIXEIRA, J. B. Micropropagation of Miconia sp. a woody melastomaceae from Brazil, using thidiazuron as plant growth regulator. Revista Brasileira de Fisiologia Vegetal, Brasília, v. 9, n. 1, p. 21-25, 1997.

DONADIO, L. C.; MÔRO, F. V.; SERVIDONE, A. A. Frutas brasileiras. Jaboticabal: Editora da UNESP, 2002. 288p.

FIOR, C. S.; RODRIGUES, L. R.; CALIL, A. C.; LEONHARDT, C.; SOUZA, L. S.; SILVA, V. S. Qualidade fisiológica de sementes de guabijuzeiro (Myrcianthes pungens (Berg) Legrand - Myrtaceae) em armazenamento. Revista Árvore, Viçosa-MG, v. 34 , n. 3, p. 435-442, 2010.

GRATTAPAGLIA, D.; MACHADO, M. A. Micropropagação. In: TORRES, A. C.; CALDAS, L. S.; BUSO, J. A. Cultura de tecidos e transformação genética de plantas. Brasília: Embrapa/SPI: CNPH, 1998. v. 1, p. 183-260.
HANRY, I. S.; THORPE, T. A. Regeneration os plantlets through organogenesis from matures embryos of jack pine. Plant cell, tissue and org culture, Ariel, v.37, p. 150-164, 1994.

HUBNER, H. I.; SILVA, L. V.; CAPATTI, I.; FUMAGALI, E.; SOUTO, E. R.; GONÇALVES, R. A. C.; OLIVEIRA, A. J. B. Multiplicação in vitro de Aspidosperma ramiflorum Muell. Arg. (Apocynaceae). Acta Scientiarum. Health Sciences, Maringá, v.29, p. 63-66, 2007.

LATTUADA, D. Micropropagação e Miniestaquia de pitangueira (Eugenia uniflora L.). 75f. Dissertação (Mestrado em Fitotecnia) - Universidade Federal do Rio Grande do Sul, Porto Alegre, 2010.

LIEW, T. K.; TEO, C. K. H. Multiple shoot production in vitro of the tropical timber tree, sentang ( $\mathrm{Aza}$ dirachta excelsa Linn.). HortScience, Alexandria, v. 33, n. 6, p. 1073-1075, 1998.

LLOYD, G.; McCOWN, B. Commercially-feasible micropropagation of mountain laurel, Kalmia latifólia, by use of shoot-tip culture. Combined Proceedings International Plant Propagators Society, Seattle, v.30, p.421-427, 1980.

LORENZI, H. Árvores brasileiras: manual de identificação e cultivo de plantas arbóreas nativas do Brasil. Nova Odessa : Plantarum, 2002. v.1,265p.

MARCHIORI, J. N. C.; SOBRAL, M. Dendrologia das angiospermas: Myrtales. Santa Maria: UFSM, 1997. 304p.

MATTOS, J. R. de. Fruteiras nativas do Sul do Brasil In: SIMPÓSIO NACIONAL DE RECURSOS GENÉTICOS DE FRUTEIRAS NATIVAS, 1992, Cruz das Almas. Anais... Cruz das Almas: EMBRAPACNPMF, 1993. p. 35-50.

NASCIMENTO, A.C.; PAIVA, R.; NOGUEIRA, R. C.; PORTO, J. M.; NOGUEIRA, G.; SOARES, F. P. AIB e BAP no cultivo in vitro de Eugenia pyriformis Cambess. Revista Acadêmica. Ciências Agrárias e Ambientais, Curitiba, v.6, n.2, p.223-228, 2008

PÁDUA, T. Propagação das árvores frutíferas. Informe Agropecuário, Belo Horizonte, v.9, n.101, p.11-19, 1983. 
PICOLOTTO, L.; SHUCH, M. W.; SOUZA, J. A.; SILVA, L. C.; FERRI, J.; FACHINELLO, J. C. Efeito do hipoclorito de sódio, fotoperíodo e temperatura no estabelecimento in vitro de jabuticabeira. Scientia Agraria, Curitiba, v.8, n.1, p.19-23, 2007.

ROCHA, S. C. Micropropagação da canjarana (Cabralea canjerana). 2005. 74f. Dissertação (Mestrado em Botânica) - Universidade Federal do Paraná, Curitiba, 2005.

ROGALSKI, M.; GUERRA, M. P.; SILVA, A. L. multiplicação in vitro da ameixeira 'Santa Rosa' :efeito da citocinina BAP. Revista Brasileira de Fruticultura, Jaboticabal, v. 25, n. 2, p. 365-367, 2003.

SANTANA, D. G.; RANAL, M. A. Análise da germinação: um enfoque estatístico. Brasília: Editora da Universidade de Brasília, 2004. 248 p.

SILVA, H. R. Morfologia e lignificação de calos de Eucalyptus grandis (Hill ex Maiden) sob efeito de cinetina e ácido 2,4-diclorofenoxiacético. 2007.79 f. Dissertação (Mestrado em Ciência Ambientais e Florestais) - Universidade Federal Rural do Rio de Janeiro, Seropédica, 2007.
SILVA, J. B. C.; NAKAGAWA, J. 1995. Estudos de fórmulas para cálculo de germinação. Informativo ABRATES, Londrina, v. 5, n. 1, p. 62-73.

SOUZA, J. A.; SCHUCH, M. W.; DONINI, L. P.; RIBEIRO, M. F. Tipos e concentrações de citocinina na multiplicação in vitro de pitangueira. Ciências Rural, Santa Maria, v.38, n.7, 2008.

SOUZA, J. Propagação in vitro de fruteiras nativas: araçá (Psidium Cattleyanum Sabine), feijoa (Acca selowiana (Berg) Burret) e pitanga (Eugenia uniflora L.). 2007. 125f. Tese (Doutorado em Fruticultura de Clima Temperado)- Faculdade de Agronomia, Universidade Federal de Pelotas, Pelotas, 2007.

UEMATSU, C.; TSUJIMOTO, M.; SUGIMOTO, M. In vitro Propagation of Eugenia uniflora L. Plant Biotechnology, Sheffield, v.16, n.21, p.159-162, 1999. 